\title{
ARTICLE \\ Hypophagia induced by hindbrain serotonin is mediated through central GLP-1 signaling and involves 5-HT2C and 5-HT3 receptor activation
}

\author{
Rosa M. Leon ${ }^{1}$, Tito Borner ${ }^{2}$, David J. Reiner ${ }^{1}$, Lauren M. Stein ${ }^{1}$, Rinzin Lhamo ${ }^{1}$, Bart C. De Jonghe ${ }^{2}$ and Matthew R. Hayes ${ }^{1,2}$
}

The overlap in neurobiological circuitry mediating the physiological and behavioral response to satiation and noxious/stressful stimuli are not well understood. The interaction between serotonin (5-HT) and glucagon-like peptide-1 (GLP-1) could play a role as upstream effectors involved in mediating associations between anorectic and noxious/stressful stimuli. We hypothesize that 5-HT acts as an endogenous modulator of the central GLP-1 system to mediate satiation and malaise in rats. Here, we investigate whether interactions between central 5-HT and GLP-1 signaling are behaviorally and physiologically relevant for the control of food intake and pica (i.e., behavioral measure of malaise). Results show that the anorexia and body weight changes induced by administration of exogenous hindbrain 5-HT are dependent on central GLP-1 receptor signaling. Furthermore, anatomical evidence shows mRNA expression of 5-HT2C and 5-HT3 receptors on GLP-1-producing preproglucagon (PPG) neurons in the medial nucleus tractus solitarius by fluorescent in situ hybridization, suggesting that PPG neurons are likely to express both of these receptors. Behaviorally, the hypophagia induced by the pharmacological activation of both of these receptors is also dependent on GLP-1 signaling. Finally, 5-HT3, but not 5- $\mathrm{HT} 2 \mathrm{C}$ receptors, are required for the anorectic effects of the interoceptive stressor $\mathrm{LiCl}$, suggesting the hypophagia induced by these $5-\mathrm{HT}$ receptors may be driven by different mechanisms. Our findings highlight 5-HT as a novel endogenous modulator of the central GLP-1 system and suggest that the central interaction between $5-\mathrm{HT}$ and GLP-1 is involved in the control of food intake in rats.

Neuropsychopharmacology (2019) 44:1742-1751; https://doi.org/10.1038/s41386-019-0384-x

\section{INTRODUCTION}

Many of the brain nuclei involved in processing information regarding the control of food intake are the same nuclei involved in mediating the physiological, behavioral, and endocrine response to stress. This overlap in neuroendocrine circuitry is thought to be, in part, responsible for the bidirectional relationship that exists between energy balance and the physiological responses to interoceptive stress or noxious stimuli [1]. The ingestion of food produces physiological responses similar to those initiated by stress, including increased plasma levels of glucocorticoids [2], adrenocorticotropic hormone [3], and epinephrine [4]. Although the role of classical stress centers-such as the hypothalamic-pituitary-adrenal axis (HPA) - in mediating such effects are well-established, much less is known about the upstream neurobiological substrates involved in partitioning the downstream effector circuitry and behavioral outputs of the physiological responses to noxious/stressful stimuli from those of normal ingestive behavior. The central serotonin (5-HT) and glucagon-like peptide-1 (GLP-1) systems are both involved in regulating the physiological responses to stress/noxious stimuli, as well as the control of food intake [5-17]. This overlap in biological function in combination with a growing body of literature supporting an interaction between 5-HT and the GLP-1 [18-24] has generated considerable interest in these systems as potential candidate upstream effectors.

GLP-1 is an anorectic hormone involved in the control of food intake [7, 25, 26], glycemic control [27], stress [8-11], and nausea $[28,29]$. Centrally, GLP-1 is produced by preproglucagon (PPG) neurons located predominately in the nucleus tractus solitarius (NTS), which send projections to GLP-1-receptor (GLP-1R)-expressing nuclei throughout the brain [30]. PPG neurons are activated by ingestion of large meals [31], multiple satiation signals (e.g., gastric distension [32] and cholecystokinin [33]), as well as various interoceptive stressors (e.g., lipopolysaccharides [8], lithium chloride [10, 11], and cisplatin [28]). Despite the growing appreciation of the downstream nuclei targeted by central PPG neurons, upstream signaling mechanisms that facilitate endogenous PPG activation in response to these stimuli remains unknown.

Similar to the central GLP-1 system, the central serotonergic system reduces food intake [13], regulates central stress centers (such as the HPA) [14, 16], and mediates nausea, malaise and emesis [34]. In addition, 5-HT is critically important for a number of neurobiological functions (e.g., mood, reward, appetite, attention) [35] and is a common target for therapeutics, including the most commonly used type of antidepressant (selective 5 -HT reuptake inhibitors) $[36,37]$. Although the enterochromaffin cells of the

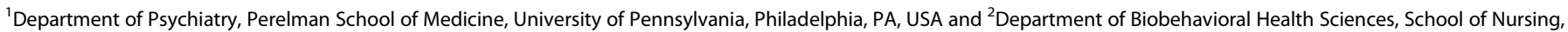
University of Pennsylvania, Philadelphia, PA, USA

Correspondence: Matthew R. Hayes (hayesmr@pennmedicine.upenn.edu)

Received: 2 January 2019 Revised: 1 March 2019 Accepted: 30 March 2019

Published online: 8 April 2019 
small intestine produce $\sim 90 \%$ of the body's total 5 - HT [38] content, a small percent of $5-\mathrm{HT}$ is produced in the central nervous system (CNS), mainly within the Raphe nuclei [39]. These serotonergic neurons exhibit widespread projections throughout the brain, signaling through its large and complex receptor system, comprised of 14 different functional receptor subtypes [40]. Although multiple 5-HTRs are expressed within the NTS [4143], the 5-HT2C receptors (5-HT2CR) and 5-HT3 receptors (5-HT3R) are of particular interest given their excitatory properties [40], anorectic effects [44-46], role in the development of illness-like behaviors [47, 48], and clinical relevance. Indeed, both the 5HT2CR agonist, Lorcaserin, and the 5-HT3R antagonist, Zofran, are FDA-approved to treat obesity and emesis, respectively.

5-HT and GLP-1 interact bidirectionally at a cellular and molecular level in the periphery (e.g., plasma [21], colon [23, 49], and ileum [19]) and in the CNS [22, 24]. Holt et al. [24], showed that in mice, $50-80 \%$ of NTS PPG neurons are innervated by serotonergic projections and that treatment with $5-\mathrm{HT}$ leads to increased calcium spikes in PPG neurons. These results suggest that, at least within the NTS, the directionality of this interaction favors 5-HT acting as a modulator of PPG neuron activity. However, whether this directionality is maintained in rats and what the underlying mechanisms and behavioral consequences are of this interaction remain unexplored. Here, we sought to investigate the role of 5-HT as a regulator of PPG neurons in the regulation of energy balance, specifically as it relates to hypophagia and malaise/nausea in rats. The three main goals of this study were to: (1) determine whether 5-HT engages the central GLP-1 system to induce hypophagia and kaolin intake, (2) assess the role of the $5-\mathrm{HT} 2 \mathrm{CR}$ and $5-\mathrm{HT} 3 \mathrm{R}$ in mediating these effects, and (3) investigate whether the 5-HT/GLP-1 interaction is also involved in mediating the hypophagia induced by the interoceptive stressor, $\mathrm{LiCl}$.

\section{MATERIALS AND METHODS}

\section{Animals}

Male Sprague Dawley rats (350-365 g upon arrival; Charles River) were individually housed in hanging wire cages maintained at $23^{\circ} \mathrm{C}(12 \mathrm{~h}$ reversed light/dark cycle) and given ad libitum chow (Purina LabDiet 5001) and water. All procedures were approved by Institutional Animal Care and Use Committees at the University of Pennsylvania and were performed in accordance with National Institute of Health animal experimentation guidelines.

\section{Drugs and delivery sites}

The competitive GLP-1R antagonist, exendin-(9-39) (Ex9; Bachem, 4017799), serotonin chloride (5-HT; Tocris, 3547), selective 5HT2CR agonist, lorcaserin (Lor; KeyOrganics, KS1439), and selective 5-HT3R agonist, SR57227 (SR5; Tocris, 1205), were all dissolved in artificial cerebrospinal fluid (aCSF; Harvard Apparatus, 59-7316). The selective 5-HT3R antagonist, ondansetron (OND; Tocris, 2891), and 5-HT2CR antagonist, RS102221 (RS1; Tocris, 3969) were dissolved in $100 \%$ dimethyl sulfoxide (DMSO, Research Organics, 2166D). LiCl (Sigma, L4408) was prepared as a $0.15 \mathrm{~m}$ solution in $0.9 \%$ sterile saline and administered intraperitoneally (i.p.) in a volume of $20 \mathrm{ml} / \mathrm{kg}(127.2 \mathrm{mg} / \mathrm{kg})$. Aside from $\mathrm{LiCl}$, all other drugs were administered centrally in a $1 \mu \mathrm{l}$ volume into either the 4th ventricle (4th intracerebroventricular (ICV)) or lateral ventricle (LV). The 4th ICV site of administration was selected to specifically target the hindbrain (avoiding the effects of the drug(s) in the forebrain) and because of its anatomical proximity to the NTS. Ex9 was delivered into the LV to theoretically produce a whole-brain CNS blockade of GLP-1Rs.

\section{Stereotaxic surgery}

Animals were anesthetized with an intramuscular injection of an anesthetic cocktail (KAX) composed of ketamine (Butler Schein;
$90 \mathrm{mg} / \mathrm{kg}$ ), acepromazine (Midwest Veterinary Supply; $0.64 \mathrm{mg} /$ $\mathrm{kg}$ ), and xylazine (Midwest Veterinary Supply; $2.7 \mathrm{mg} / \mathrm{kg}$ ) and placed in a stereotaxic apparatus after reaching proper anesthesia depth. Single guide cannulae (26 gauge; Plastics One, Roanoke, VA) targeting the 4th ICV and/or LV were implanted (4th ICV coordinates: midline, $2.5 \mathrm{~mm}$ anterior to the occipital suture, the indwelling cannula aimed $5.2 \mathrm{~mm}$ ventral to skull; LV coordinates: $1.6 \mathrm{~mm}$ to the right of the midline, $0.9 \mathrm{~mm}$ posterior to bregma, internal cannula aimed $2.8 \mathrm{~mm}$ ventral to skull; Paxinos and Watson, 2005) and affixed to the skull with bone screws and dental cement. Analgesia (meloxicam; Midwest Veterinary Supply; $2 \mathrm{mg} / \mathrm{kg}$ ) was administered subcutaneously for the first 3 days following surgery. Rats were given 1 week to recover from surgery before starting behavioral testing. For microinjections, 33 gauge microinjector (Plastics One) that extended an additional $2.0 \mathrm{~mm}$ beyond the length of the cannula were used. Fourth ventricle cannula placements were verified by assessing the hyperglycemic response to 5 -thio-D-glucose $(210 \mu \mathrm{g} / 2 \mu \mathrm{l})$, as described previously [50]. The LV placement was verified with angiotensin II $(10 \mathrm{ng} / 1 \mu \mathrm{l})$ drinking test [51]. Verifications were conducted prior to starting behavioral testing, only animals that passed their relative verifications were tested.

\section{Fluorescent in situ hybridization (FISH)}

Tissue harvest. Rats $(n=4)$ were anesthetized with KAX and decapitated. Brains were quickly removed, frozen in cold hexane (Honeywell), and stored at $-80^{\circ} \mathrm{C}$. Coronal sections $(20 \mu \mathrm{m})$ containing the dorsal vagal complex/NTS at the level of the obex ( 14.15-14.64 $\mathrm{mm}$ posterior to bregma) were obtained using a cryomicrotome (Leica Microsystem) and immediately mounted onto Superfrost Plus slides (Fisher).

mRNA expression of PPG, 5-HT2CR, and 5-HT3R at the level of the medial NTS. FISH was carried out using RNAscope Multiplex Fluorescent Reagent Kit V2 (Cat. 323100; Advanced Cell Diagnostics (ACDBio), Hayward, CA) per manufacturer's protocol. In brief, slide mounted sections were rinsed in $4 \%$ paraformaldehyde for $15 \mathrm{~min}$ at room temperature (RT). Following two quick rinses in $0.1 \mathrm{M}$ phosphate-buffered saline (PBS), the sections were dehydrated in ascending ethanol solutions ( 5 min washes in $50,70,100$, $100 \%$ ethanol) followed by an overnight incubation in $100 \%$ ethanol at $-20^{\circ} \mathrm{C}$. Next, slides were air-dried and a hydrophobic barrier was made around all of the sections on the slide using a hydrophobic pen (Vector Labs). The sections were treated with $\mathrm{H}_{2} \mathrm{O}_{2}$ for $10 \mathrm{~min}$ at RT (followed by $3 \times 1 \mathrm{~min}$ in PBS) and Protease IV for $30 \mathrm{~min}$ at RT (followed by $2 \times 1$ min rinses in PBS).

Pre-treated tissue sections were processed immediately using probes designed by ACD to detect PPG mRNA (Rn-Gcgs-C3; 315471-C3), 5-HT2C mRNA (Rn-Htr2c-C2; 469321-C2), and 5-HT3A mRNA (Rn-Htr3a; 480041). Sections were incubated in a cocktail containing all three probes (concentrations indicated by manufacturer) for $2 \mathrm{~h}$ at $40^{\circ} \mathrm{C}$ in a HybEZ ${ }^{\mathrm{TM}}$ oven (ACDBio). Slides were rinsed twice in RNAscope wash buffer followed by a series of amplification steps at $40^{\circ} \mathrm{C}$ separated by two brief washes in RNAScope wash buffer (ACDBio): $30 \mathrm{~min}$ FL v2 AMP1 (ACDBio; 320852), 15 min FL v2 AMP2 (ACDBio; 320853), 30 min FL v2 AMP3 (ACDBio; 320854), and then 15 min FL v2 AMP4A (ACDBio 320855; C1 Alexa $488 \mathrm{~nm}$; C2, Atto $550 \mathrm{~nm}$; C3 Atto $647 \mathrm{~nm}$ ). After the final wash buffer, slides were coverslipped using Fluorogel mounting medium with DAPI (Fisher).

Image acquisition, processing, and quantification. Sections were visualized with a Leica SP5 $X$ confocal microscope using the $\times 20$ and $\times 40$ oil-immersion objectives and the $405,488,555$, and 647 laser lines. Image $z$-stacks were collected with the $\times 20$ and $\times 40$ oil-immersion objective with a step size of $2 \mu \mathrm{m}$; at $\times 40$ a $\times 2-4$ optical zoom was used to image individual neurons. All images were collected sequentially to avoid contamination of signals from 
other fluorophores. The collected $z$-stack images were processed to reduce background and create three-dimensional rotational animations using Imaris 8.1.2 (Bitplane). Every PPG neuron that was identified at the level of the obex (14.15-14.64 $\mathrm{mm}$ posterior to bregma) was quantified in each section that was imaged. Colocalization of 5-HTRs on PPG neurons was quantified manually on Imaris following background subtraction. All images were taken within 5 days of completing FISH and all sections coming from the same animal were imaged on the same day to limit difference in fluorescence.

\section{Feeding behavior}

In these studies, kaolin intake (i.e., pica) was used as a model of illness-like behaviors (i.e proxy for nausea/malaise). Pica is the ingestion of a non-nutritive material, such as clay (or in a lab setting kaolin pellets) in response to toxicosis. As rodents lack the vomiting reflex, kaolin intake has been established as a model of malaise in rats [52]. A series of behavioral, pharmacological, and molecular techniques were employed to test the hypothesis that activation of 5-HT2CR and 5-HT3R modulates central GLP-1 signaling to influence food intake and pica.

General procedures. Rats were handled daily, pre- and postsurgery, and were habituated to ICV and i.p. injections for 5 consecutive days before beginning experimentation. Drug injections were performed immediately prior to the onset of the dark cycle unless otherwise specified. For experiments measuring ad libitum food intake, food weights were recorded to the $\sim 0.1 \mathrm{~g}$, accounting for spillage. Chow intake was measured at 1, 3, 6, and $24 \mathrm{~h}$ post injection and body weight was measured at 0 and $24 \mathrm{~h}$ post injection. To measure pica, rats were habituated to a second hopper containing kaolin pellets (Research Diets, K50001) for 5-7 days week prior to testing. Following 2-4 days of habituation, $24 \mathrm{~h}$ baseline chow and kaolin intake readings were taken for $1-2 \mathrm{~d}$ before testing begun. During testing, kaolin intake was recorded at 0 and $24 \mathrm{~h}$ post injection, accounting for spillage. Treatments were assigned using a within-subject counterbalanced design and separated by $48 \mathrm{~h}$ between injections, except when noted.

Effect of GLP-1R blockade on 5-HT-induced suppression of chow intake and increased kaolin intake. Rats $(n=30)$ received a 4th ICV injection of $5-\mathrm{HT}(40 \mu \mathrm{g})$ or aCSF followed by LV injection of Ex9 $(20 \mu \mathrm{g})$ or aCSF. The dose of $5-\mathrm{HT}$ was chosen based on previous published and unpublished work from our laboratory examining 5-HT-mediated suppression of food intake [53]. The dose of Ex9 was chosen based on literature indicating this dose is subthreshold [54] and does not, on its own, increase food intake. Chow intake and body weight were measured as described in general procedures. Following habituation and baseline testing (see general procedures for details), the effects of $40 \mu \mathrm{g}$ of $5-\mathrm{HT}$ (4th ICV) on kaolin intake was measured in a separate group of rats $(n=13)$. Chow intake, body weight, and kaolin intake were measured as described in general procedures.

Effects on chow intake, kaolin intake, and body weight induced by pharmacological agonists targeting 5-HT2CR or 5-HT3R. Rats received 4th ICV injections of either Lor $(0,2,10$, or $20 \mu \mathrm{g} ; n=$ 9) or SR5 $(0,5,10$, or $20 \mu g ; n=11)$. Chow intake was measured as described in general procedures. Experimental procedures for each agonist were run in separate cohorts of rats. Effect of Lor $(n=8)$ and SR5 $(n=21)$ on $24 \mathrm{~h}$ body weight and $24 \mathrm{~h}$ kaolin intake was measured in a separate group of rats $(20 \mu \mathrm{g} 4$ th ICV for both agonists).

Effect of central blockade of GLP-1R signaling on 5-HT2CR- and 5HT3R-induced chow and kaolin intake. Rats were treated with Ex9 $(20 \mu \mathrm{g} ; \mathrm{LV})$ or aCSF following treatment with either Lor or aCSF $(n=20)$, or SR5 or aCSF ( $n=19)$ ( $20 \mu \mathrm{g} 4$ th ICV for both agonists). Experimental procedures for each of these agonists were run in separate cohorts of rats. Chow intake, body weight, and kaolin intake were measured as described in general procedures.

Validation of RS102221. First, a dose-response analysis of RS1 (5HT2CR antagonist) was conducted in a group of animals ( $n=16)$. In this cohort, chow intake was measured following 4th ICV treatment with either $0,10,20,40 \mu \mathrm{g}$ of RS1. A separate cohort of rats $(n=10)$ was pre-treated with $40 \mu \mathrm{g}$ of RS1 ( $40 \mu \mathrm{g}$; 4th ICV) followed by Lor $(20 \mu \mathrm{g} ; 4$ th ICV) and chow intake was measured at 1 and $3 \mathrm{~h}$ post injection.

Effect of hindbrain blockade of specific of 5-HTR subtypes on LiClinduced chow intake suppression. Rats were pre-treated with either the RS1 $(40 \mu \mathrm{g} ; n=8)$ or DMSO, or OND $(25 \mu \mathrm{g} ; n=14)$ or DMSO (4th ICV for both agonists), this was followed by a systemic injection with $\mathrm{LiCl}(127.2 \mathrm{mg} / \mathrm{kg}$; i.p.) or saline. Experimental procedures for each of these antagonists were run in separate cohorts of rats. Chow intake was measured at 1 and $3 \mathrm{~h}$ post injections.

\section{Statistical analyses}

All data are represented as mean \pm SEM with the a-level set to $p=$ 0.05 . For behavioral studies, the data are binned and analyzed using either a repeated measures two-way analysis of variance (ANOVA) followed by a Newman-Keuls post hoc analysis when appropriate or a repeated measures one-way ANOVA followed by a Dunnet post hoc analysis when appropriate.

\section{RESULTS}

Central blockade of GLP-1Rs attenuated the anorectic and body weight-reducing effects of hindbrain $5-\mathrm{HT}$

The effect of hindbrain administration of 5-HT on chow intake, body weight, and kaolin intake was measured in a group of rats ( $n=18$ ) by administering $40 \mu \mathrm{g}$ of $5-\mathrm{HT}$ (4th ICV). At this dose, $5-\mathrm{HT}$ decreased chow intake at 1, 3, 6, and $24 \mathrm{~h}$ post injection, decreased $24 \mathrm{~h}$ body weight, and increased $24 \mathrm{~h}$ kaolin intake compared with vehicle-treated controls (all $p<0.01$, Figure S1a-c). To determine whether the effects of 5-HT on chow and kaolin intake were dependent on central GLP-1 signaling, a separate cohort of rats $(n=30)$ received a subthreshold dose of Ex9 $(20 \mu \mathrm{g}$; LV) following treatment with 5 -HT $(40 \mu \mathrm{g} ; 4$ th ICV). As expected, 5 HT significantly suppressed chow intake at $1,3,6$, and $24 \mathrm{~h}$ post injection and Ex9 alone had no effect (Fig. 1a). A significant interaction between $5-\mathrm{HT}$ and $\mathrm{Ex} 9$ was detected at each timepoint $\left(1 \mathrm{~h}\left(\mathrm{~F}_{1,29} \geq 7.8 ; p<0.01\right) ; 3 \mathrm{~h}\left(\mathrm{~F}_{1,29} \geq 8.4 ; \mathrm{p}<0.01\right) ; 6 \mathrm{~h}\left(\mathrm{~F}_{1,29} \geq 10.8 ;\right.\right.$ $\left.p<0.01) ; 24 h\left(F_{1,29} \geq 12.3 ; p<0.01\right)\right)$. Post hoc analyses revealed that treatment with Ex9 reversed the anorectic effects of 5-HT at all timepoints (Newman-Keuls; all $p<0.01$ ). Ex9 also reversed the reduction in $24 \mathrm{~h}$ body weight induced by $5-\mathrm{HT}\left(\mathrm{F}_{1,29} \geq 4.2 ; p<\right.$ 0.05 ) (Fig. 1b). In another group of animals $(n=13)$ in which $24 \mathrm{~h}$ kaolin intake was measured, there was a main effect of $5-\mathrm{HT}$ $\left(\mathrm{F}_{1,12} \geq 11.1 ; p<0.01\right)$, however, treatment with Ex9 did not attenuate this effect (Fig. 1c). It is worth noting that this lack of effect is owing in part to a high degree of variability in the 5-HT/ Ex9 treatment, which is driven by one animal that did not consume any kaolin $(0 \mathrm{~g})$ after $5-\mathrm{HT}$ alone but consumed $2.4 \mathrm{~g}$ of kaolin following the 5-HT/Ex9 combo treatment. Furthermore, of the animals that presented a pica response in the 5-HT alone treatment, all but one rat showed decreased levels of kaolin intake following the $5-\mathrm{HT} / \mathrm{Ex} 9$ combo treatment.

Heterogeneous mRNA expression of $5-\mathrm{HT} 2 \mathrm{R}$ and $5-\mathrm{HT} 3 \mathrm{R}$ on rat PPG neurons in the medial NTS

Fluorescent in situ hybridization was conducted on coronal sections containing medial NTS (mNTS) at the level of obex (Fig. 2a), to determine whether PPG neurons (blue) express 
a

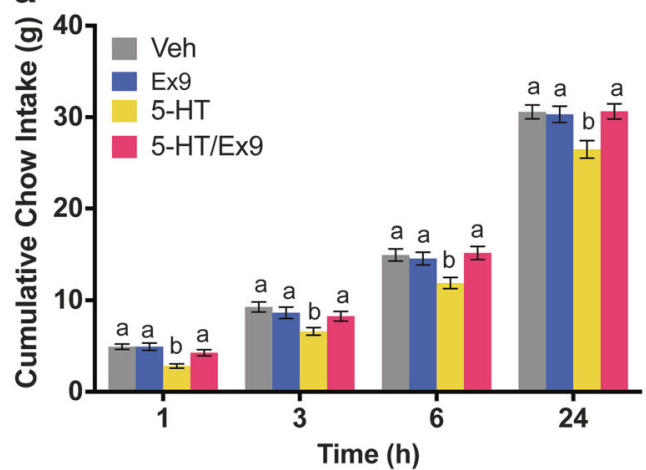

b

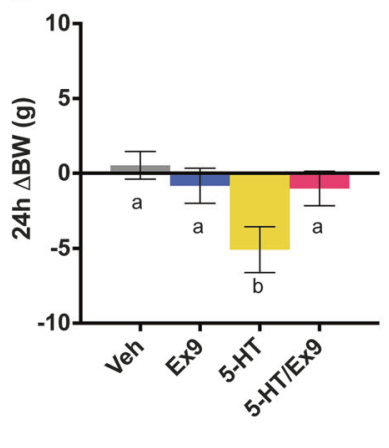

C

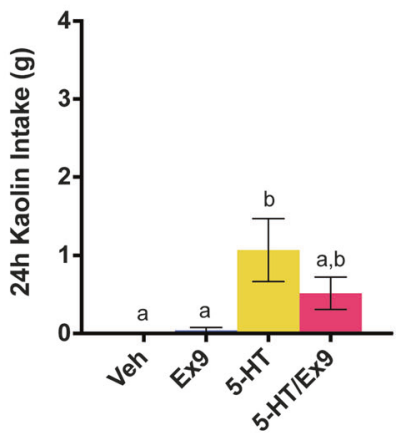

Fig. 1 Central blockade of GLP-1R signaling reverses the effects of a hindbrain administration of 5-HT. Treatment with 5-HT (40 $\mu \mathrm{g}$, 4th ICV) was followed by $20 \mu \mathrm{g}$ of the GLP-1R antagonist, Exendin-9 (Ex9) into the LV ( $n=30)$. This dose of Ex9 had on its own had no effect on food intake but was able to reverse the anorectic effects of $5-\mathrm{HT}$ at $1,3,6$, and $24 \mathrm{~h}$ post injection a and prevents the reduction in body weight seen $24 \mathrm{~h}$ post injection $\mathbf{b}$. In a sub-cohort $(n=13)$ in which kaolin intake was measured $5-\mathrm{HT}$ increased kaolin intake but treatment with Ex9 did not significantly attenuate that effect $\mathbf{c}$. Data were analyzed using a two-way ANOVA, different letters are significantly different from each other $(p<0.05)$ according to Newman-Keuls post hoc analyses
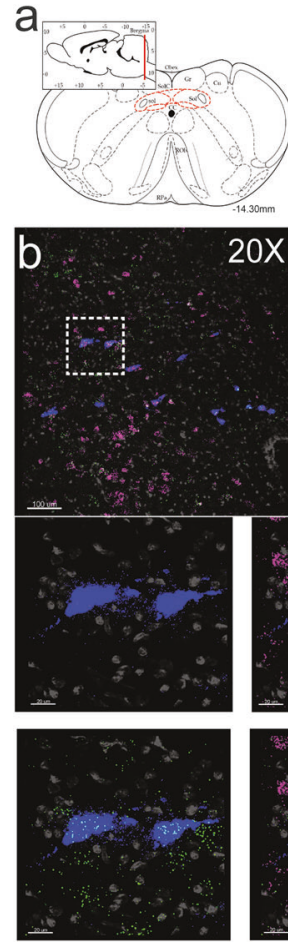
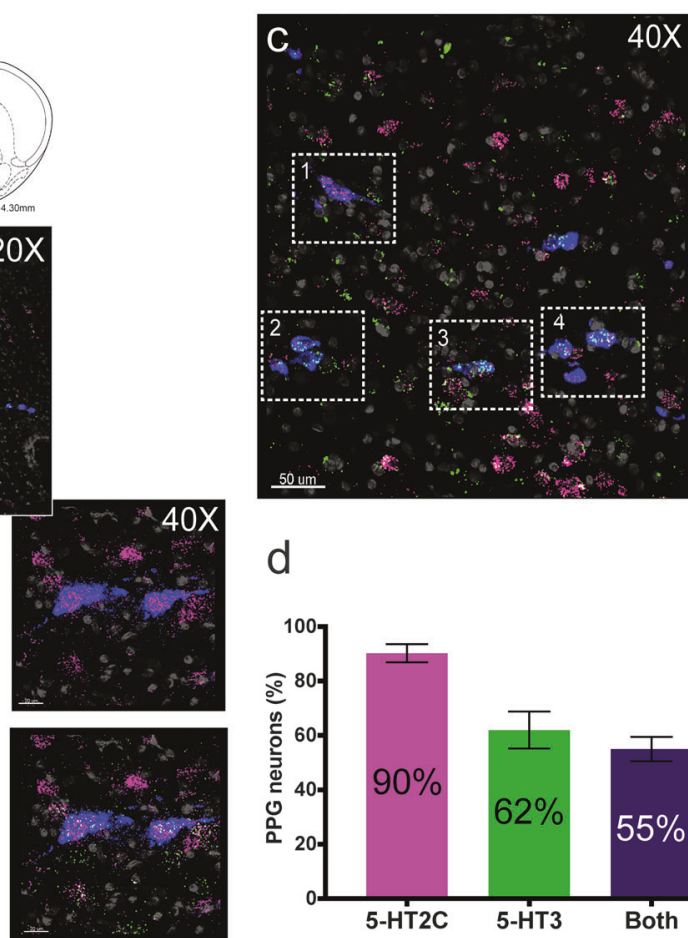

d

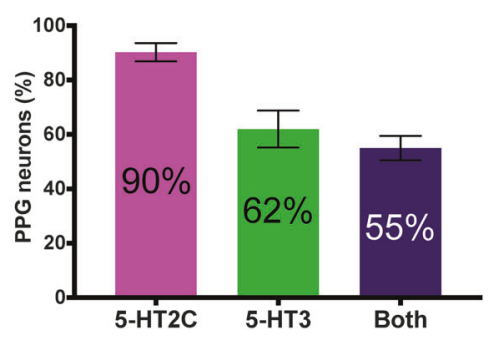

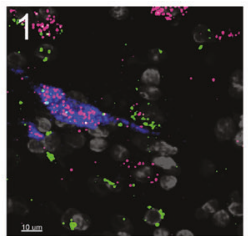
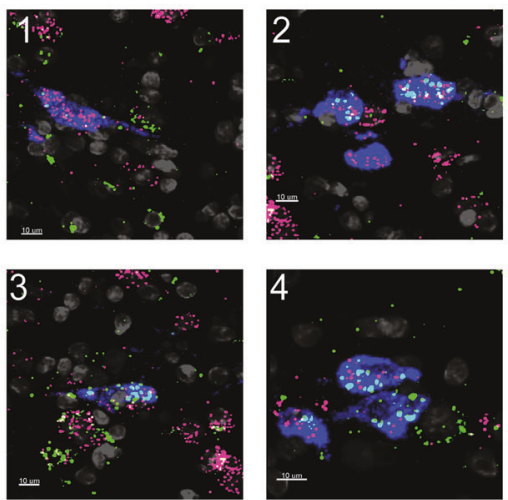

e

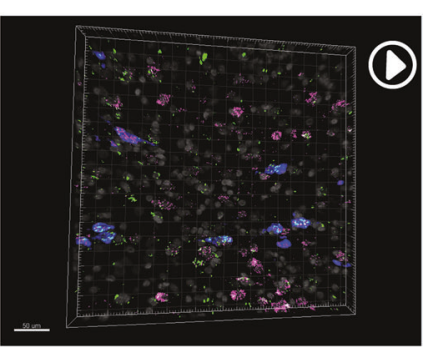

Fig. 2 Expression of 5-HT2CR and 5-HT3R mRNA on rat PPG neurons in the medial NTS. FISH was conducted on medial NTS sections (20 $\mu$ m), obtained at the level of the obex $(14.15-14.64 \mathrm{~mm}$ posterior to bregma) a, using probes for PPG, 5-HT2CR, and 5-HT3R ( $n=4$ ). A representative NTS section at $\times 20$ magnification is shown in b, PPG are shown in blue, 5-HT2CR in magenta, 5-HT3R in green, and DAPI in gray. The dotted box in $\mathbf{b}$ is further magnified $(\times 40)$ in subpanels, these highlight colocalization between PPG neurons (top left) with 5-HT2CR (top right), 5-HT3R (bottom left), or both (bottom right) b. There is a high degree of heterogeneity in the expression level of the 5-HTRs on PPG neurons $\mathbf{c}$. The dotted boxes in c are further magnified (1-3 optical zoom) in subpanels to the right (subpanels 1-4 correspond to the dotted boxes), these show individual the variability in mRNA expression of 5-HT2CR and 5-HT3R between PPG neurons About $90 \%$ of PPG neurons at this level of the NTS express 5-HT2Rs, $62 \%$ express $5-\mathrm{HT} 3 \mathrm{R}$, and 55\% co-express both receptors d. Representative three-dimensional rotational video showing colocalization of 5-HT2R and 5-HT3R on PPG neurons. This video is taken from a $z$-stack (2 mm step size) collected from the mNTS at the level of the obex with the $\times 40$ oil-immersion objective and a $2-4$ optical zoom e

$5-\mathrm{HT} 2 \mathrm{CR}$ (magenta) and 5-HT3R (green) transcripts $(n=4$; 3-5 sections per animal were imaged). Colocalization of PPG with 5-HT2CR and 5-HT3R transcripts (Fig. 2b) indicates that rat PPG neurons in the mNTS transcribe message for both of these serotonergic receptor subtypes. There was a high degree of heterogeneity observed in the mRNA expression levels of these receptors among PPG neurons, some PPG neurons expressed mainly the 5- $\mathrm{HT} 2 \mathrm{C}$, whereas others expressed both transcripts to varying degrees (Fig. 2c). The heterogeneity seemed to be random, with no detectable patterns of expression in rostralcaudal or medial-lateral plane. In addition, there were no differences in expression between hemispheres. A threedimensional rotation video of $40 \times z$-stack overlays looking at 5HTRs on PPG neurons corroborated the colocalization, showing 
a

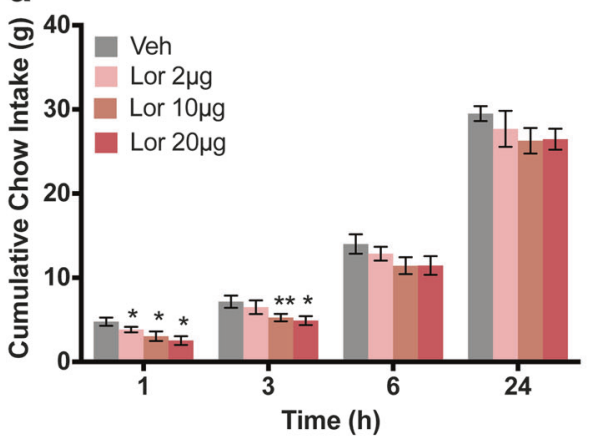

d

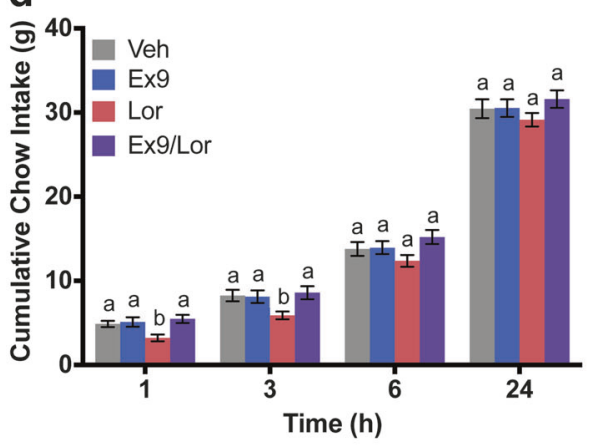

b

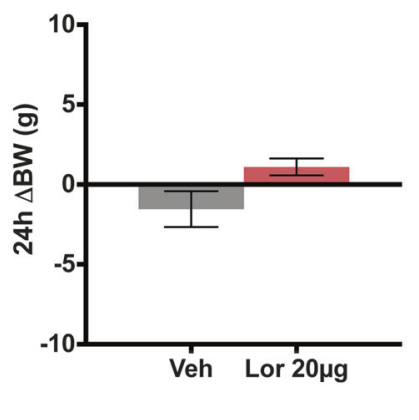

e

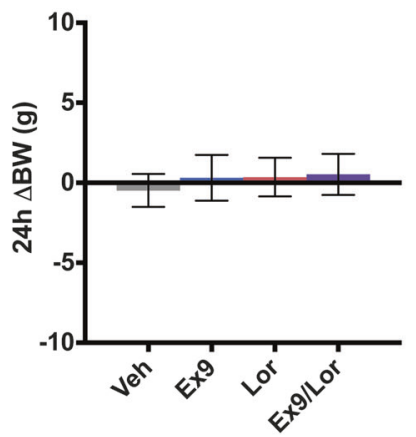

C

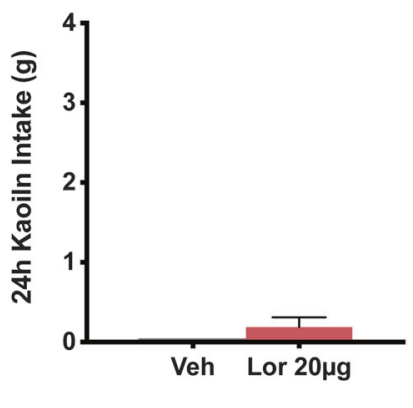

f

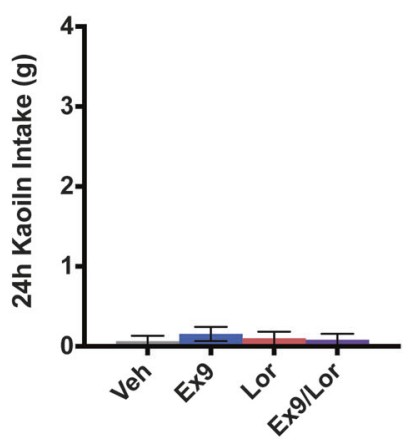

Fig. 3 Activation of hindbrain 5-HT2CR suppresses chow intake without affecting kaolin intake and is dependent on central GLP-1 signaling. The 5-HT2CR agonist, Lorcaserin (Lor) was delivered (4th ICV) using the following doses: 0 (aCSF), 2, 10, or 20 $\mu \mathrm{g}$ a-c $(n=9)$. At $1 \mathrm{~h}$ post injection all tested doses of Lor reduce chow intake, at $3 \mathrm{~h}$ only the $10 \mu \mathrm{g}$ and $20 \mu \mathrm{g}$ doses cause a significant reduction a. In a separate cohort $(n=8)$ the effect of $20 \mu \mathrm{g}$ Lor (4th ICV) on $24 \mathrm{~h} \mathrm{BW}$ and kaolin intake were measured b-c. At this dose Lor did not affect $24 \mathrm{~h}$ body weight b nor kaolin intake c. Treatment with Ex9 reverses the anorectic effect of Lor seen at 1 and $3 \mathrm{~h} \mathbf{d}(n=20)$. Lor and Ex9 alone or in combination have no effect on $24 \mathrm{~h}$ body weight e nor kaolin intake f. A repeated measures one-way ANOVA and Dunnet post hoc ${ }^{*} p<0.05$, ${ }^{* *} p<0.01$ ) was used in $3 a$, whereas a paired $t$ test was used for $\mathbf{b}-\mathbf{c}$. Data in $\mathbf{d}-\mathbf{f}$ were analyzed using a two-way ANOVA, different letters are significantly different from each other $(p<0.05)$ according to Newman-Keuls post hoc analyses

the transcripts for these receptors expressed within PPG neuron as opposed to adjacent to them (Fig. 2d). This approach avoids the possibility of false overlaps that may exist in the two-dimensional images. Quantification revealed that $90 \%$ of PPG neurons expressed $5-\mathrm{HT} 2 \mathrm{CR}$ mRNA, 62\% of PPG neurons expressed 5HT3R mRNA, and $55 \%$ of PPG neurons expressed mRNA for both receptors (data were calculated as average expression per animal) (Fig. 2e).

Activation of hindbrain 5-HT2CR acutely suppressed feeding without affecting malaise, an effect that is dependent on central GLP-1 signaling

The 5-HT2CR agonist, Lorcaserin (Lor), is well characterized [55] and has extensively been used systemically in rodents to show its intake suppressive effects $[56,57]$. However, we could not find a study looking at the anorectic effects of Lor following central administration. We therefore began by performing a dose-response analysis in order to identify a central (4th ICV) Lor dose that would induce a similar acute anorectic effect to the ones observed following systemic administration [57]. Lor was administered at $0,2,10$, and $20 \mu \mathrm{g}(n=9)$, a main effect of Lor on chow intake was detected at 1 and $3 \mathrm{~h}\left[1 \mathrm{~h}\left(\mathrm{~F}_{3,24} \geq 6.8 ; p<0.01\right)\right.$; $\left.3 \mathrm{~h}\left(\mathrm{~F}_{3,24} \geq 4.4 ; p<0.05\right)\right]$, but not at 6 and $24 \mathrm{~h}$. All three doses decreased chow intake at $1 \mathrm{~h}$, whereas only the 10 and $20 \mu \mathrm{g}$ doses caused a significant decrease in chow intake at $3 \mathrm{~h}$ (Dunnet; all $p<0.05$ ) (Fig. 3a). To assess whether nausea/malaise contributed to the intake suppression following hindbrain activation of $5-\mathrm{HT} 2 \mathrm{CR}$, kaolin intake was measured in a separate group of rats
( $n=8$ ) receiving $20 \mu \mathrm{g}$ of Lor (4th ICV). At this dose, Lor had no effect on $24 \mathrm{~h}$ body weight (Fig. 3b) or kaolin intake (Fig. 3c).

To determine whether central GLP-1 signaling is necessary for the 5-HT2CR-induced anorectic effect, rats were treated with Ex9 $(20 \mu \mathrm{g} ; \mathrm{LV})$ following a 4th ICV injection $20 \mu \mathrm{g}$ of Lor $(n=20)$ (Fig. 3d-f). A significant interaction between Lor and Ex9 was detected at 1 and $3 \mathrm{~h}\left(1 \mathrm{~h}\left(\mathrm{~F}_{1,19} \geq 5.898 ; p<0.05\right) ; 3 \mathrm{~h}\left(\mathrm{~F}_{1,19} \geq 10.48\right.\right.$; $p<0.01)$ ). Post hoc analyses reveal that Ex9 reversed the anorectic effects of 4th ICV Lor at 1 and $3 \mathrm{~h}$ post injection (Newman-Keuls; all $p<0.01$ ) (Fig. 3d). Lor and Ex9 alone or in combination had no effect on $24 \mathrm{~h}$ body weight (Fig. 3e) or $24 \mathrm{~h}$ kaolin intake (Fig. 3f). These findings indicated 5-HT2CR activation within the hindbrain suppresses food intake in a GLP-1-dependent manner, without eliciting nausea/malaise.

Activation of hindbrain 5-HT3R suppressed $24 \mathrm{~h}$ food intake, an effect that is dependent on central GLP-1 signaling

The 5-HT3R agonist, SR57227 (SR5), acutely suppresses food intake in rodents upon peripheral administration [58]. Owing to a lack of published data regarding its effect upon central administration we first performed a dose-response analysis to identify a central (4th ICV) dose of SR5 that would induce a comparable anorectic effect to a systemic administration [58]. SR5 was injected at 0, 5, 10, and $20 \mu \mathrm{g}(n=11)$, a main effect of SR5 on chow intake was detected at all timepoints $\left[1 \mathrm{~h}\left(\mathrm{~F}_{3,30} \geq 7.0 ; p<0.01\right) ; 3 \mathrm{~h}\left(\mathrm{~F}_{3,30} \geq 4.3 ; p>0.05\right)\right.$; $\left.6 \mathrm{~h}\left(\mathrm{~F}_{3,30} \geq 8.0 ; p<0.001\right) ; 24 \mathrm{~h}\left(\mathrm{~F}_{3,30} \geq 6.6 ; p<0.01\right)\right]$. The $5 \mu \mathrm{g}$ dose significantly suppressed chow intake at $6 \mathrm{~h}$, whereas the $20 \mu \mathrm{g}$ dose decreased chow intake at all timepoints (Dunnet; all $p<0.05$ ) 
a

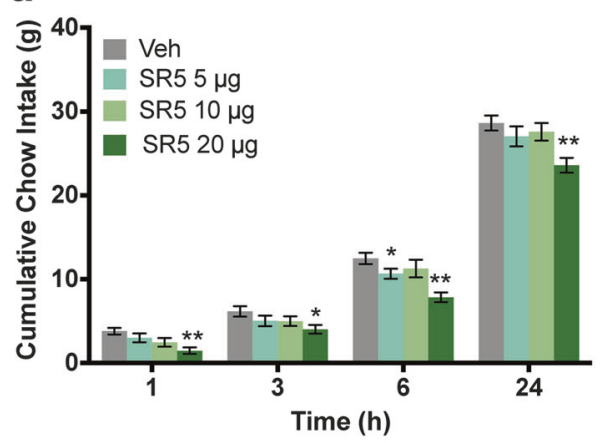

d

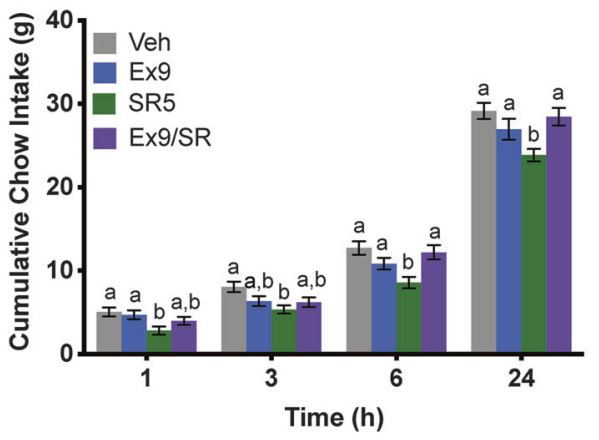

b

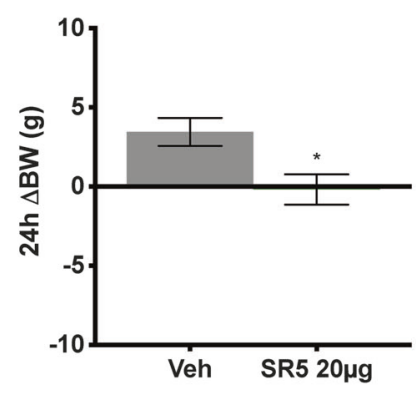

e

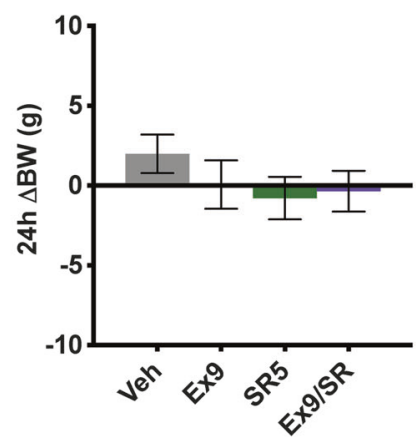

C

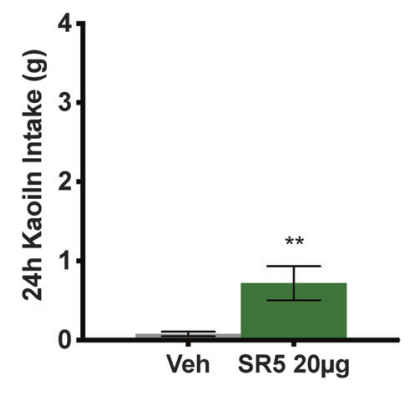

f

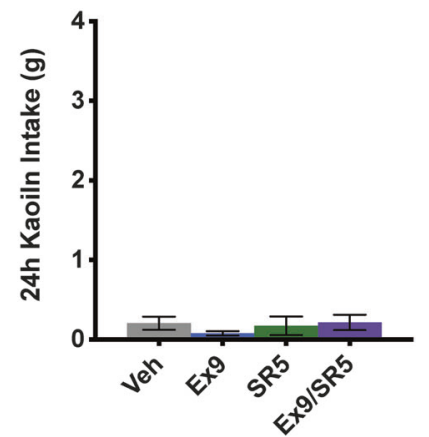

Fig. 4 Activation of hindbrain 5-HT3R suppresses chow intake and is dependent on central GLP-1 signaling. The 5-HT3R agonist, SR57227 (SR5) was delivered (4th ICV) using the following doses: 0 (aCSF), 5, 10, or $20 \mu \mathrm{g}$ a-c $(n=11)$. Only the highest dose (20 $\mu \mathrm{g})$ of SR5 suppresses chow intake, this suppression was significant at all timepoints. a A $20 \mu \mathrm{g}$ treatment with SR5(4th ICV) prevents BW gain seen in the control group $\mathbf{b}$ and increases kaolin intake $\mathbf{c}(n=21)$. The effect of central blockade of GLP-1Rs was tested in a separate cohort $(n=19)$. Treatment with Ex9 reverses the anorectic effect of SR5 at 6 and $24 \mathrm{~h}$, but not at 1 and $3 \mathrm{~h} \mathbf{d}(n=19)$. SR5 and Ex 9 alone or in combination have no effect on $24 \mathrm{~h}$ body weight e or kaolin intake f. A repeated measures one-way ANOVA and Dunnet post hoc $\left({ }^{*} p<0.05,{ }^{* *} p<0.01\right)$ was used in $3 a$, whereas a paired $t$ test was used for $\mathbf{b}-\mathbf{c}$. Data in $\mathbf{d}-\mathbf{f}$ were analyzed using a two-way ANOVA, different letters are significantly different from each other $(p<0.05)$ according to Newman-Keuls post hoc analyses

(Fig. 4a). To determine whether malaise/nausea contributed to this effect $24 \mathrm{~h}$ kaolin intake was measured in a separate cohort $(n=$ 21). Treatment with $20 \mu \mathrm{g}$ of SR5 (4th ICV) prevented the $24 \mathrm{~h}$ body weight gain that was observed in the vehicle-treated rats and increased kaolin intake (all $p<0.01$; Fig. $4 \mathrm{~b}, \mathrm{c}$ ).

To assess whether central GLP-1 signaling is required for the anorectic effects induced by hindbrain activation of 5-HT3R, rats were treated with Ex9 $(20 \mu \mathrm{g} ; \mathrm{LV})$ following a 4th ICV injection of SR5 $(20 \mu \mathrm{g})(n=19 ;$ Fig. $4 d-f)$. As expected, Ex9 alone had no effect on any of the behaviors measured. Similar to what was observed in the dose-response, there was a main effect of SR5 on chow intake at all timepoints $\left(1 \mathrm{~h}\left(\mathrm{~F}_{1,18} \geq 23.97 ; p<0.001\right) ; 3 \mathrm{~h}\right.$ $\left(\mathrm{F}_{1,18} \geq 20.26 ; p<0.001\right) ; 6 \mathrm{~h}\left(\mathrm{~F}_{1,18} \geq 7.522 ; p<0.05\right) ; 24 \mathrm{~h}\left(\mathrm{~F}_{1,18} \geq\right.$ 8.617; $p<0.001)$ ). A significant interaction between SR5 and Ex9 was detected at all timepoints $\left(1 \mathrm{~h}\left(\mathrm{~F}_{1,18} \geq 6.197 ; p<0.05\right) ; 3 \mathrm{~h}\right.$ $\left(\mathrm{F}_{1,18} \geq 9.675 ; p<0.01\right) ; 6 \mathrm{~h}\left(\mathrm{~F}_{1,18} \geq 15.88 ; p<0.001\right) ; 24 \mathrm{~h}\left(\mathrm{~F}_{1,18} \geq\right.$ 27.3; $\mathrm{p}<0.001)$ ). Post hoc analyses reveal that Ex9 reversed the anorectic effects of SR5 at 6 and $24 \mathrm{~h}$ (Newman-Keuls; all $p<0.01$ ), but not at 1 and $3 \mathrm{~h}$ post injection (Fig. 4d). Interestingly, SR5 alone or in combination with Ex9 showed no effect on $24 \mathrm{~h}$ body weight (Fig. 4e) or kaolin intake (Fig. 4f). SR5 produces a reliable anorectic effect that extends to $24 \mathrm{~h}$ post injection. At this dose, however, it does not seem to produce a consistent effect on pica. These results suggest that activation of hindbrain 5-HT3R suppresses chow intake and that, unlike the anorectic effect caused by activation of hindbrain 5-HT2CR, this suppression involves a partial engagement of mechanisms related to malaise, although there appears to be individual differences in the magnitude of pica behavior to brainstem 5-HT3R activation.
Hindbrain blockade of 5-HT3R, but not 5-HT2CR, reversed LiClinduced chow intake suppression

The anorectic effects of the interoceptive stressor $\mathrm{LiCl}$ is mediated, in part, by the central GLP-1 system. Systemic (i.p.) administration of $\mathrm{LiCl}$ activates NTS PPG neurons as shown by increased c-FOS expression [10]. In addition, central (ICV) treatment with a GLP-1R antagonist significantly attenuates the anorectic effect [11] and pica response [59] induced by systemic $\mathrm{LiCl}$. Given the evidence that hindbrain 5-HT has a modulatory effect on central GLP-1 signaling and that this effect seems to involve the activation of 5HT2CR and 5-HT3R, we investigated whether pharmacologically blocking these receptors would be sufficient to attenuate the anorectic effect induced by systemic $\mathrm{LiCl}$. Based on our data thus far, we hypothesized that hindbrain activation of 5-HT3R, but not the 5-HT2CR, helps mediate the anorexia induced by $\mathrm{LiCl}$.

The behavioral effects of the 5-HT2C antagonist, RS102221 [60], have only been studied in the context of locomotor activity [61] and anxiety-like behavior [62]. Therefore, we first sought to validate its effectiveness as a $5-\mathrm{HT} 2 \mathrm{CR}$ antagonist in the context of food intake. Fourth ventricular administration of RS1 at 10, 20, or $40 \mu \mathrm{g}$ did not increase chow intake $(n=16)$ (Figure S2a). However, a pre-treatment with RS1 $(40 \mu \mathrm{g})$ significantly reversed the anorectic effect induced by 4th ICV Lor at $1 \mathrm{~h}(n=10)\left(\mathrm{F}_{1,9} \geq\right.$ 20.17; $p<0.01$ ) (Figure S2b). Next, we tested whether a subthreshold dose of RS1 (a dose that would not have an effect on feeding behavior on its own) could attenuate the anorectic effect induced by $\mathrm{LiCl}$ [127.2 mg/kg; a dose known to elicit anorectic effects [63]. Treatment with $\mathrm{LiCl}$ did not alter $24 \mathrm{~h}$ body weight, but significantly suppressed chow intake and increased $24 \mathrm{~h}$ kaolin 
a
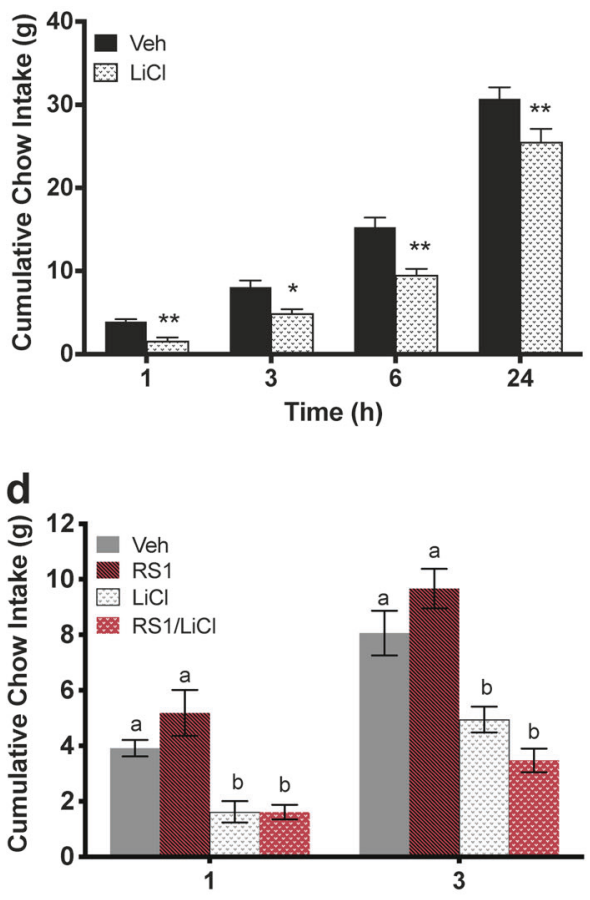

Time (h) b
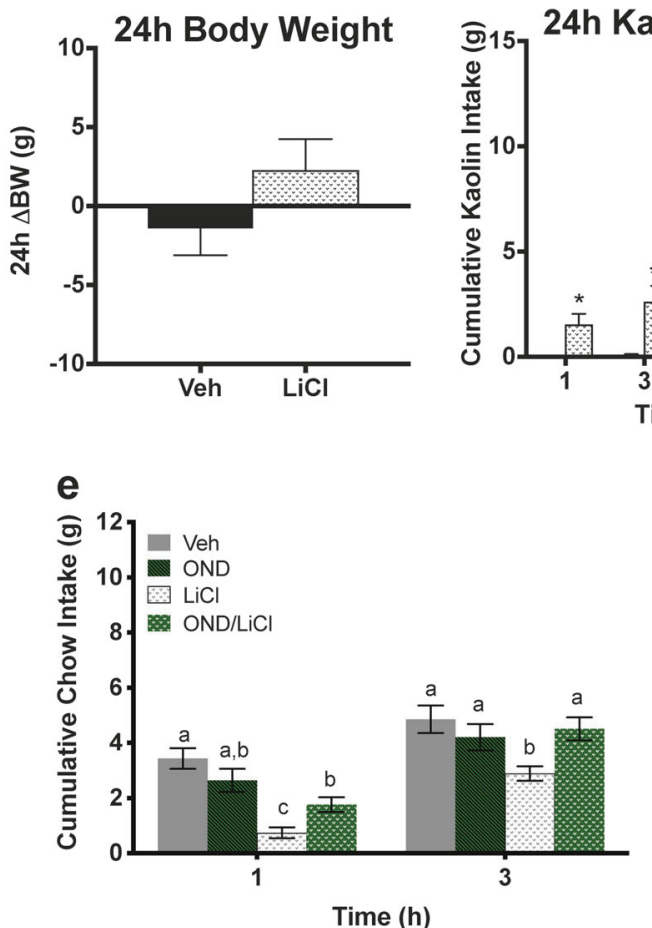

Fig. 5 Hindbrain blockade of 5-HT3R, but not 5-HT2CR, reverses the acute anorectic effects of systemic LiCl. Pre-treatment with the 5-HT3R antagonist, OND ( $25 \mu \mathrm{g} ; 4 \mathrm{~V} ; n=14)$, or the 5 -HT2CR antagonist, RS1 ( $40 \mu \mathrm{g} ; 4 \mathrm{~V} ; n=8)$, pre-treatment was followed by LiCl (127.2 mg/kg; i.p). At this dose, $\mathrm{LiCl}$ significantly suppresses chow intake $\mathbf{a}$ and increases kaolin intake at all timepoints $\mathbf{b}$ but has no effect on body weight $\mathbf{c}$. Pretreatment with RS1 had no effect $\mathbf{d}$ on the $\mathrm{LiCl}$-induced anorexia. The LiCl-induced suppression of chow intake was attenuated at $1 \mathrm{~h}$ and reversed at $3 \mathrm{~h}$ by pre-treatment with OND e. Chow intake was analyzed using a two-way ANOVA at each timepoint, different letters are significantly different from each other $(p<0.05)$ according to Newman-Keuls post hoc analyses

intake (all $p>0.01, \mathrm{~S} 1 \mathrm{a}-\mathrm{c})$ (Fig. 5a-c). Rats $(n=8)$ received RS1 (40 $\mu \mathrm{g} ; 4$ th ICV) followed by a systemic (i.p.) injection of $\mathrm{LiCl}(127.2$ $\mathrm{mg} / \mathrm{kg}$ ). Chow intake was measured at $1,3,6$, and $24 \mathrm{~h}$, but only 1 and $3 \mathrm{~h}$ of cumulative chow intake are shown in the figure (this applies to Fig. $5 \mathrm{~d}$, e). A main effect of $\mathrm{LiCl}$ was detected at all timepoints $\left(1 \mathrm{~h}\left(\mathrm{~F}_{1,7} \geq 27.13 ; p<0.01\right) ; 3 \mathrm{~h}\left(\mathrm{~F}_{1,7} \geq 92.79 ; p<0.001\right)\right)$. Post hoc analyses reveal revealed RS1-pre-treatment had no effect on chow intake at any timepoint (Fig. $5 \mathrm{~d}$ ).

Next, we tested if the blockade of 5-HT3R via OND would could attenuate the $\mathrm{LiCl}$-induced anorexia. The dose of OND was chosen based on literature indicating that $25 \mu \mathrm{g}$ of OND (4th ICV) has no effect on chow intake [64]. Rats $(n=14)$ received OND $(25 \mu \mathrm{g} ; 4$ th ICV) followed by a systemic (i.p.) $\mathrm{LiCl}(127.2 \mathrm{mg} / \mathrm{kg})$. In this case, a significant interaction between OND and $\mathrm{LiCl}$ was present at 1 and $3 \mathrm{~h}$ [1 h $\left.\left(\mathrm{F}_{1,13} \geq 10.94 ; p<0.01\right) ; 3 \mathrm{~h}\left(\mathrm{~F}_{1,13} \geq 7.991 ; p<0.005\right)\right]$. Post hoc analyses reveal that pre-treatment OND attenuated the anorectic effect of $\mathrm{LiCl}$ at $1 \mathrm{~h}$ and reversed it at $3 \mathrm{~h}$ post injection (all $p<0.05$ ) (Fig. 5e).

\section{DISCUSSION}

The central GLP-1 system is engaged by physiological satiation signals, as well as noxious stimuli, toxins, and stressful stimuli (see $[65,66]$ for review). In an attempt to uncover a novel neural substrate responsible for engaging the complementary and diverse set of physiological/behavioral outputs from the central GLP-1 system, we focused our attention on the central serotonergic system due to its action as a satiation signal $[13,46]$ and mediator of stress $[14,16]$ and malaise responses [34]. Here, we show that the hypophagic effects of hindbrain $5-\mathrm{HT}$ is dependent on central GLP-1R signaling. This 5-HT-mediated activation of central GLP-1 signaling was further shown to be mediated by
5-HT2CR and 5-HT3R. To this end, FISH analyses revealed mRNA expression of both 5-HT2CR and 5-HT3R within PPG neurons in the medial NTS. The hypophagia induced by specific agonists of these receptors in the hindbrain was also shown to be reversed by blockade of CNS GLP-1R by LV administration of Ex9. Finally, although the hypophagia induced by activation of hindbrain 5HT3R was shown to involve a partial engagement of illness-like behaviors, activation of $5-\mathrm{HT} 2 \mathrm{CR}$ suppressed food intake via a GLP-1 dependent mechanism devoid of this behavior. These results suggest that the hypophagia induced by hindbrain activation of the 5-HT2CR and 5-HT3R is driven by different behavioral mechanisms (e.g., satiation vs. noxious mediated hypophagia, respectively). Collectively, these results indicate that the interaction between $5-\mathrm{HT}$ and GLP-1 within the hindbrain is relevant for the control of food intake, an effect that seems to involve activity of the 5-HT2CR and 5-HT3R.

The interaction between $5-\mathrm{HT}$ and GLP-1 is bidirectional and site specific [22, 24]. Of note, a recent study by Holt [24] showed within the NTS, 5-HT signaling has a modulatory effect on central GLP-1 signaling in mice. In trying to understand whether this effect is achieved through a direct modulation, we looked at mRNA expression of 5-HT2C and 5-HT3 receptor subtypes on PPG neurons. Although many of the $5-\mathrm{HT}$ receptor subtypes, including the $5-\mathrm{HT} 2 \mathrm{C}$ and $5-\mathrm{HT} 3$, are expressed in the NTS $[41,42]$, the phenotype of these cell population(s) remain unclear. Using FISH, we observed expression of 5-HT2CR and 5-HT3R transcripts within rat PPG neurons in the medial NTS. Transcript receptor expression was heterogenous, with the 5-HT2CR being more commonly expressed than the 5-HT3R. Intriguingly, these data differ from previous reports in which the presence of $5-\mathrm{HT} 2 \mathrm{CR}$, but not 5HT3R, was detected in PPG neurons of mice using an electrophysiological approach [24]. Given that 5-HT3R does not always 
engage calcium signaling when activated but instead can depolarize the cell via $\mathrm{Na}+$ [67] it would be useful to obtain anatomical verification of 5-HT3R expression on PPG neurons in mice, as well other animal models, especially those with a vomiting reflex such as the shrew, ferret, dog, or primate. Although difference in methodological approaches used could play a role in the distinction between these findings, species differences within the GLP-1 system are not uncommon. Some of these differences between rat and mice include effects on glucose metabolism [68, 69], anatomical distribution of PPG neurons [70, 71], and of relevance to the current data, a divergence in behavioral responses mediated by the central GLP-1 system to noxious stimuli [72].

Central blockade of GLP-1Rs prevented hindbrain 5-HT-induced hypophagia and reduction of $24 \mathrm{~h}$ body weight. These results provide further evidence that within the hindbrain, $5-\mathrm{HT}$ has a modulatory effect on CNS GLP-1 signaling and supports the hypothesis that $5-\mathrm{HT}$ is a putative upstream modulator of central GLP-1 signaling. The inability of Ex9 to significantly attenuate the kaolin intake induced by hindbrain 5-HT could result from an insufficient dose of Ex9 reaching the nuclei directly involved in the production of illness-like behaviors, the heterogeneity in pica responses observed between animals, and/or additional non-GLP1 neuronal substrates also contributing to illness-like behaviors. Given that GLP-1Rs are expressed widely throughout the brain and many nuclei are involved in regulating various GLP-1 functions, our approach was to deliver Ex9 $(20 \mu \mathrm{g})$ into the LV with the goal of inducing a global CNS blockade of GLP-1 signaling. Although this approach is useful in determining whether central GLP-1 signaling as a whole is involved, a caveat of this approach is that the rate of diffusion and biodistribution of Ex9 throughout the brain cannot be controlled. As a result, more caudal GLP-1R-expressing nuclei, including those expressed in the "vomiting center" (e.g., NTS/area postrema), may have received a less-effective dose of Ex9.

Hindbrain activation of 5-HT2CR and 5-HT3R independently suppressed chow intake in a central GLP-1-dependent manner. Through dose-response analyses, a central dose of $20 \mu \mathrm{g}$ (4th ICV) was identified as sufficient to trigger the anorectic effects of Lor and SR5. At this dose the 5-HT2CR agonist, Lor, caused an acute suppression of food intake that was significant at 1 and $3 \mathrm{~h}$ post injection without affecting $24 \mathrm{~h}$ body weight or kaolin intake. These results are in line with previous reports showing a shortlived anorectic effect following systemic 5-HT2CR activation and lack of effect on body weight following a single peripheral administration [56, 57]. In contrast, $20 \mu \mathrm{g}$ of the 5-HT3R agonist, SR5, led to a much longer anorectic effect that was significant up to $24 \mathrm{~h}$ post injection. Although the magnitude and duration of the anorectic effect of SR5 was reliable and consistent between experiments, the same could not be said for its effects on $24 \mathrm{~h}$ body weight and kaolin intake. This lack of consistency suggests that the anorectic effects of SR5 at this dose only involves a partial engagement of mechanisms related to malaise. To further explore the role that malaise and stress-induced hypophagia play in mediating the anorectic effects induced by hindbrain activation of $5-\mathrm{HT} 2 \mathrm{CR}$ and $5-\mathrm{HT} 3 \mathrm{R}$, we conducted experiments using the interoceptive stressor, $\mathrm{LiCl}$. Instead of using 5-HTR agonists to induce aversive effects, we used pharmacological antagonists of the 5-HT2CR and 5-HT3R to try to prevent the anorexia induced by $\mathrm{LiCl}$. Pre-treatment with OND, but not RS1, block the anorexia caused by systemic $\mathrm{LiCl}$. These results indicate that the $5-\mathrm{HT} 3 \mathrm{R}$, but not the $5-\mathrm{HT} 2 \mathrm{CR}$, is required for the effects of this stressor on food intake.

The behavioral differences observed following pharmacological manipulations of the 5-HT2CR and 5-HT3R highlight a temporal and potentially behavioral dissociation between the mechanisms driving anorectic effects induced by these different 5-HTRs. Specifically, it is likely that the anorectic effects induced by hindbrain activation of 5-HT2CR and 5-HT3R are driven by a set of partially overlapping mechanisms involving satiety and malaise, respectively. This is supported by a previous report in which OND was able to attenuate the nausea-induced conditioned gaping effects of systemic $\mathrm{LiCl}$ [73]. However, we stress that a wealth of future research is needed to further disentangle the contribution of these two 5-HT receptor subtypes in engaging PPG neurons in response to both physiological and pathophysiological stimuli that suppress food intake and potentially engage illness-like behaviors.

Collectively, the data presented show that central GLP-1 signaling is required for the anorectic and body weight changes induced by hindbrain $5-\mathrm{HT}$, an effect that is mediated, at least in part by the activation of both 5-HT2CR and 5-HT3R expressed on PPG neurons. Future studies will pursue a more in-depth analysis of other behavioral/physiological effects that could be influenced by the central interaction between $5-\mathrm{HT}$ and GLP-1, as well as try to identify the central source of $5-\mathrm{HT}$ that is responsible for activation of PPG neurons. Among the caudal nuclei that compose the Raphe and project to the hindbrain, the Raphe Magnus contains the highest density of 5-HT neurons [74] and has been shown to project to the NTS $[75,76]$, making it a prime candidate as a potential upstream regulator of the GLP-1 system. Importantly, our findings set forth $5-\mathrm{HT}$ as a novel endogenous modulator of the central GLP-1 system and suggest that the central interaction between $5-\mathrm{HT}$ and GLP-1 is relevant for the control of food intake.

\section{FUNDING AND DISCLOSURE}

This research was supported by NIH- R01-DK115762 (MRH), R01DK112812 (BCD), SNF P2ZHP3_178114 (TB), F32DK118818 (LMS), and F31DK118816 (RML). MRH has received research support, not used in the current studies, from investigator-initiated sponsored proposals from Novo Nordisk, Zealand Pharma, and BoehringerIngelheim. BCD has received research support, not used in the current studies, from investigator-initiated sponsored proposals from Zealand Pharma and Pfizer. All other authors declare no potential conflicts of interest. DJR's affiliation is the Behavioral Neuroscience Research Branch, IRP-NIDA-NIH, Baltimore, MD.

\section{ACKNOWLEDGEMENTS}

We thank Celina Nhan, Jack Chen, Nina Juntereal, Anh Cao, Claudia Liberini, and Samantha Fortin for valuable technical assistance.

\section{AUTHOR CONTRIBUTIONS}

RML: conceptualization of experimental hypotheses, designing research studies, conducting experiments, acquiring and analyzing data, writing the manuscript. TB: designing research studies, analyzing data, writing the manuscript. DJR: conducting experiments, acquiring data, manuscript revisions. LMS: conducting experiments, manuscript revisions. RL: conducting experiments and acquiring data. BCD: conceptualization, writing, and revising manuscript. $\mathrm{MRH}$ : conceptualization of the experimental hypotheses, designing research studies, analyzing data, writing the manuscript.

\section{ADDITIONAL INFORMATION}

Supplementary Information accompanies this paper at (https://doi.org/10.1038/ s41386-019-0384-x).

Publisher's note: Springer Nature remains neutral with regard to jurisdictional claims in published maps and institutional affiliations.

\section{REFERENCES}

1. Ulrich-Lai YM, Ryan KK. Neuroendocrine circuits governing energy balance and stress regulation: functional overlap and therapeutic implications. Cell Metab. 2014;19:910-25. 
2. Moberg GP, Bellinger LL, Mendel VE. Effect of meal feeding on daily rhythms of plasma corticosterone and growth hormone in the rat. Neuroendocrinology. 1975;19:160-9.

3. Slag MF, et al. Meal stimulation of cortisol secretion: a protein induced effect. Metabolism. 1981;30:1104-8.

4. Steffens $A B$, et al. Meal-induced increases in parasympathetic and sympathetic activity elicit simultaneous rises in plasma insulin and free fatty acids. Physiol Behav. 1986;37:119-22.

5. Turton MD, et al. A role for glucagon-like peptide-1 in the central regulation of feeding. Nature. 1996;379:69-72.

6. Barrera JG, et al. Hyperphagia and increased fat accumulation in two models of chronic CNS glucagon-like peptide-1 loss of function. J Neurosci. 2011;31:3904-13.

7. Barrera JG, et al. GLP-1 and energy balance: an integrated model of short-term and long-term control. Nat Rev Endocrinol. 2011;7:507-16.

8. Grill $\mathrm{HJ}$, et al. Attenuation of lipopolysaccharide anorexia by antagonism of caudal brain stem but not forebrain GLP-1-R. Am J Physiol Regul Integr Comp Physiol. 2004;287:R1190-3.

9. Holt MK, Trapp S. The physiological role of the brain GLP-1 system in stress. Cogent Biol. 2016;2:1229086.

10. Rinaman L. Interoceptive stress activates glucagon-like peptide-1 neurons that project to the hypothalamus. Am J Physiol. 1999;277:R582-90.

11. Rinaman L. A functional role for central glucagon-like peptide-1 receptors in lithium chloride-induced anorexia. Am J Physiol. 1999;277:R1537-40.

12. Kinzig KP, et al. CNS glucagon-like peptide-1 receptors mediate endocrine and anxiety responses to interoceptive and psychogenic stressors. J Neurosci. 2003;23:6163-70.

13. Pollock JD, Rowland N. Peripherally administered serotonin decreases food intake in rats. Pharm Biochem Behav. 1981;15:179-83.

14. Heisler LK, et al. Serotonin activates the hypothalamic-pituitary-adrenal axis via serotonin 2C receptor stimulation. J Neurosci. 2007;27:6956-64.

15. Lam DD, Heisler LK. Serotonin and energy balance: molecular mechanisms and implications for type 2 diabetes. Expert Rev Mol Med. 2007:9:1-24.

16. Bagdy G, et al. Serotonin agonists cause parallel activation of the sympathoadrenomedullary system and the hypothalamo-pituitary-adrenocortical axis in conscious rats. Endocrinology. 1989;125:2664-9.

17. Owens MJ, Nemeroff CB. Role of serotonin in the pathophysiology of depression: focus on the serotonin transporter. Clin Chem. 1994;40:288-95.

18. Brunetti L, et al. Glucagon-like peptide 1 (7-36) amide (GLP-1) and exendin-4 stimulate serotonin release in rat hypothalamus. Peptides. 2008;29:1377-81.

19. Ripken $D$, et al. Nutrient-induced glucagon like peptide- 1 release is modulated by serotonin. J Nutr Biochem. 2016;32:142-50.

20. Anderberg $\mathrm{RH}$, et al. GLP-1 is both anxiogenic and antidepressant; divergent effects of acute and chronic GLP-1 on emotionality. Psychoneuroendocrinology. 2016;65:54-66

21. Nonogaki K, Kaji T. Pharmacological stimulation of serotonin 5-HT1B receptors enhances increases in plasma active glucagon-like peptide- 1 levels induced by dipeptidyl peptidase-4 inhibition independently of feeding in mice. Diabetes Metab. 2015;41:425-8

22. Owji AA, et al. Effects of intracerebroventricular injection of glucagon like peptide- 1 and its related peptides on serotonin metabolism and on levels of amino acids in the rat hypothalamus. Brain Res. 2002;929:70-5.

23. Yang $Y$, et al. Exendin-4, an analogue of glucagon-like peptide-1, attenuates hyperalgesia through serotonergic pathways in rats with neonatal colonic sensitivity. J Physiol Pharm. 2014;65:349-57.

24. Holt MK, et al. Serotonergic modulation of the activity of GLP-1 producing neurons in the nucleus of the solitary tract in mouse. Mol Metab. 2017;6:909-21.

25. Kanoski SE, et al. Peripheral and central GLP-1 receptor populations mediate the anorectic effects of peripherally administered GLP-1 receptor agonists, liraglutide and exendin-4. Endocrinology. 2011;152:3103-12.

26. Williams DL, Baskin DG, Schwartz MW. Leptin regulation of the anorexic response to glucagon-like peptide-1 receptor stimulation. Diabetes. 2006;55:3387-93.

27. Cabou $C$, et al. Brain glucagon-like peptide-1 regulates arterial blood flow, heart rate, and insulin sensitivity. Diabetes. 2008;57:2577-87.

28. Kanoski SE, et al. The role of nausea in food intake and body weight suppression by peripheral GLP-1 receptor agonists, exendin-4 and liraglutide. Neuropharmacology. 2012;62:1916-27.

29. De Jonghe $B C$, et al. Hindbrain GLP-1 receptor mediation of cisplatin-induced anorexia and nausea. Physiol Behav. 2016;153:109-14.

30. Merchenthaler I, Lane M, Shughrue P. Distribution of pre-pro-glucagon and glucagon-like peptide-1 receptor messenger RNAs in the rat central nervous system. J Comp Neurol. 1999;403:261-80.

31. Holt MK, et al. Preproglucagon neurons in the nucleus of the solitary tract are the main source of brain GLP-1, mediate stress-induced hypophagia, and limit unusually large intakes of food. Diabetes. 2019;68:21-33.
32. Hayes MR, Bradley L, Grill HJ. Endogenous hindbrain glucagon-like peptide-1 receptor activation contributes to the control of food intake by mediating gastric satiation signaling. Endocrinology. 2009;150:2654-9.

33. Trapp S, Cork SC. PPG neurons of the lower brain stem and their role in brain GLP-1 receptor activation. Am J Physiol Regul Integr Comp Physiol. 2015;309:R795-804.

34. Cubeddu LX, et al. Changes in serotonin metabolism in cancer patients: its relationship to nausea and vomiting induced by chemotherapeutic drugs. $\mathrm{Br} \mathrm{J}$ Cancer. 1992;66:198-203.

35. Berger M, Gray JA, Roth BL. The expanded biology of serotonin. Annu Rev Med. 2009;60:355-66.

36. Booij $\mathrm{L}$, et al. Predictors of mood response to acute tryptophan depletion. A reanalysis. Neuropsychopharmacology. 2002;27:852-61.

37. Delgado PL. Depression: the case for a monoamine deficiency. J Clin Psychiatry. 2000;61:7-11.

38. Gershon MD, Tack J. The serotonin signaling system: from basic understanding to drug development for functional Gl disorders. Gastroenterology. 2007;132:397-414.

39. Donovan $\mathrm{MH}$, Tecott $\mathrm{LH}$. Serotonin and the regulation of mammalian energy balance. Front Neurosci. 2013;7:36

40. Barnes NM, Sharp T. A review of central 5-HT receptors and their function. Neuropharmacology. 1999;38:1083-152.

41. Abramowski $D$, et al. Localization of the 5 -hydroxytryptamine $2 \mathrm{C}$ receptor protein in human and rat brain using specific antisera. Neuropharmacology. 1995;34:1635-45.

42. Laporte AM, et al. Quantitative autoradiographic mapping of 5-HT3 receptors in the rat CNS using [125I]iodo-zacopride and [3H]zacopride as radioligands. Synapse. 1992;10:271-81.

43. Doucet $E$, et al. Immunolabeling of the rat central nervous system with antibodies partially selective of the short form of the 5-HT3 receptor. Neuroscience. 2000;95:881-92.

44. Redman LM, Ravussin E. Lorcaserin for the treatment of obesity. Drugs Today (Barc). 2010;46:901-10

45. Mazzola-Pomietto $P$, Aulakh CS, Murphy DL. Temperature, food intake, and locomotor activity effects of a 5-HT3 receptor agonist and two 5-HT3 receptor antagonists in rats. Psychopharmacol (Berl). 1995;121:488-93.

46. D'Agostino $\mathrm{G}$, et al. Nucleus of the solitary tract serotonin $5-\mathrm{HT} 2 \mathrm{C}$ receptors modulate food intake. Cell Metab. 2018;28:619-30.e5.

47. Higgins GA, et al. Evaluation of chemically diverse $5-\mathrm{HT}(2) \mathrm{c}$ receptor agonists on behaviours motivated by food and nicotine and on side effect profiles. Psychopharmacol (Berl). 2013;226:475-90.

48. Thompson AJ, Lummis SC. The 5-HT3 receptor as a therapeutic target. Expert Opin Ther Targets. 2007;11:527-40.

49. Lund ML, et al. Enterochromaffin 5-HT cells - a major target for GLP-1 and gut microbial metabolites. Mol Metab. 2018;11:70-83.

50. Hayes MR, Skibicka KP, Grill HJ. Caudal brainstem processing is sufficient for behavioral, sympathetic, and parasympathetic responses driven by peripheral and hindbrain glucagon-like-peptide-1 receptor stimulation. Endocrinology. 2008;149:4059-68.

51. Richard JE, et al. Activation of the GLP-1 receptors in the nucleus of the solitary tract reduces food reward behavior and targets the mesolimbic system. PLoS ONE. 2015;10:e0119034.

52. Andrews PL, Horn CC. Signals for nausea and emesis: Implications for models of upper gastrointestinal diseases. Auton Neurosci. 2006;125:100-15.

53. Hayes MR, Covasa M. CCK and 5-HT act synergistically to suppress food intake through simultaneous activation of CCK-1 and 5-HT3 receptors. Peptides. 2005;26:2322-30.

54. Barrera JG, et al. Differences in the central anorectic effects of glucagon-like peptide-1 and exendin-4 in rats. Diabetes. 2009;58:2820-7.

55. Thomsen WJ, et al. Lorcaserin, a novel selective human 5-hydroxytryptamine2C agonist: in vitro and in vivo pharmacological characterization. J Pharm Exp Ther. 2008;325:577-87.

56. Higgins GA, et al. Characterization of the $5-\mathrm{HT} 2 \mathrm{C}$ receptor agonist lorcaserin on efficacy and safety measures in a rat model of diet-induced obesity. Pharm Res Perspect. 2015;3:e00084.

57. Higgins GA, et al. Lorcaserin and CP-809101 reduce motor impulsivity and reinstatement of food seeking behavior in male rats: Implications for understanding the anti-obesity property of 5-HT2C receptor agonists. Psychopharmacol (Berl). 2016;233:2841-56.

58. Li B, et al. Role of 5-HT3 receptor on food intake in fed and fasted mice. PLoS ONE. 2015;10:e0121473.

59. Seeley RJ, et al. The role of CNS glucagon-like peptide-1 (7-36) amide receptors in mediating the visceral illness effects of lithium chloride. J Neurosci. 2000;20:1616-21.

60. Bonhaus DW, et al. RS-102221: a novel high affinity and selective, 5-HT2C receptor antagonist. Neuropharmacology. 1997;36:621-9. 
Hypophagia induced by hindbrain serotonin is mediated through central... RM Leon et al.

61. Filip $M$, Cunningham KA. Serotonin $5-H T(2 C)$ receptors in nucleus accumbens regulate expression of the hyperlocomotive and discriminative stimulus effects of cocaine. Pharm Biochem Behav. 2002;71:745-56.

62. Kuznetsova EG, et al. Effect of 5-HT2C receptor antagonist RS 102221 on mouse behavior. Bull Exp Biol Med. 2006;142:76-9.

63. Lawrence $\mathrm{CB}$, Ellacott $\mathrm{KL}$, Luckman SM. PRL-releasing peptide reduces food intake and may mediate satiety signaling. Endocrinology. 2002; 143:360-7.

64. Hayes MR, Covasa M. Dorsal hindbrain 5-HT3 receptors participate in control of meal size and mediate CCK-induced satiation. Brain Res. 2006;1103:99-107.

65. Hayes MR, et al. Incretins and amylin: neuroendocrine communication between the gut, pancreas, and brain in control of food intake and blood glucose. Annu Rev Nutr. 2014;34:237-60.

66. Kanoski SE, Hayes MR, Skibicka KP. GLP-1 and weight loss: unraveling the diverse neural circuitry. Am J Physiol Regul Integr Comp Physiol. 2016;310: R885-95.

67. Stewart A, et al. Introduction of the 5-HT3B subunit alters the functional properties of $5-\mathrm{HT} 3$ receptors native to neuroblastoma cells. Neuropharmacology. 2003;44:214-23.

68. Arora $\mathrm{T}$, et al. Microbially produced glucagon-like peptide 1 improves glucose tolerance in mice. Mol Metab. 2016;5:725-30.
69. Pérez-Tilve $D$, et al. Exendin-4 increases blood glucose levels acutely in rats by activation of the sympathetic nervous system. Am J Physiol Endocrinol Metab. 2010;298:E1088-96.

70. Cork SC, et al. Distribution and characterisation of Glucagon-like peptide-1 receptor expressing cells in the mouse brain. Mol Metab. 2015;4:718-31.

71. Tang-Christensen $M$, et al. Central administration of GLP-1-(7-36) amide inhibits food and water intake in rats. Am J Physiol. 1996;271:R848-56.

72. Lachey $\mathrm{J}$, et al. The role of central glucagon-like peptide-1 in mediating the effects of visceral illness: differential effects in rats and mice. Endocrinology. 2005;146:458-62.

73. Rock EM, Parker LA. Effect of low doses of cannabidiolic acid and ondansetron on $\mathrm{LiCl}$-induced conditioned gaping (a model of nausea-induced behaviour) in rats. Br J Pharm. 2013;169:685-92.

74. Charnay Y, Léger L. Brain serotonergic circuitries. Dialogues Clin Neurosci. 2010;12:471-87.

75. Thor KB, Helke CJ. Serotonin and substance $P$ colocalization in medullary projections to the nucleus tractus solitarius: dual-colour immunohistochemistry combined with retrograde tracing. J Chem Neuroanat. 1989;2:139-48.

76. Basbaum Al, Clanton $\mathrm{CH}$, Fields HL. Three bulbospinal pathways from the rostral medulla of the cat: an autoradiographic study of pain modulating systems. J Comp Neurol. 1978;178:209-24. 